mal karyotype, we excluded his family from further analyses. We examined all available members of the family of II.15. II.15 and III.13 were balanced carriers of a t(21q22q), the same as III.14 (Fig. 2).

As shown in Fig. 1, we succeeded in investigating 10 members of the family, representatives of three generations. A grandmother (I.1) her four daughters (II.7, II.11, II.13, II.15), and her five grandchildren (III.9, III.11, III.12, III.13, III.14). The male members of second generation and their descendants could not be examined as they had emigrated. Among the 10 members of the family examined, I.1, II.11, II.13, II.15, III.9, and III.13 were balanced carriers of $\mathrm{t}(21 \mathrm{q} 22 \mathrm{q})$, while II.7, III.11, and III.12 had normal karyotypes. III.14 was a patient with Down's syndrome, who besides the structural abnormality of $G / G$ type also had one supernumerary chromosome in group G (Fig. 3).

The small number of families with $\mathrm{t}(21 \mathrm{q} 22 \mathrm{q})$ reported so far makes this type of reciprocal translo- cation very interesting from the genetic point of view. The available data seem to suggest an excess of carriers compared to cases with Down's syndrome but because of the small number of families studied no firm conclusion can be drawn (Hamerton, 1968 and 1971; Chapman et al, 1973).

LJILJANA ZERGOLLERN

Department of Pediatrics, School of Medicine, University of Zagreb, Yugoslavia

\section{REFERENCES}

Chapman, C. J., Gardner, R. J. M., and Veale, A. M. O. (1973). Segregation analysis of a large $t(21 \mathrm{q} 22 \mathrm{q})$ family. Fournal of Medical Genetics, 10, 362-366.

Hamerton, J. L. (1968). Robertsonian translocation in man: evidence for prezygotic selection. Cytogenetics, 7, 260-276.

Hamerton, J. L. (1971). Human Cytogenetics, vol. 1, p. 255; vol. 2, pp. 237-239. Academic Press, New York.

Sumner, A. T., Evans, H. J., and Buckland, R. (1971). New technique for distinguishing between human chromosomes. Nature New Biology, 232, 31-32.

Wang, H. C. and Fedoroff, S. (1972). Banding in human chromosomes treated with trypsin. Nature New Biology, 235, 52-54.

\title{
SI Units
}

With the recommended introduction of SI (Système International) Units for reporting hospital laboratory results, the Editorial Committee of the fournal of Medical Genetics has decided that these will be introduced in the journal from 1975 . It has been agreed that where the numerical value of a new unit is the same as at present, the new unit only will be used, eg, haemoglobin: $12 \mathrm{~g} / 100 \mathrm{ml}$ will now be expressed as $12 \mathrm{~g} / \mathrm{dl}$. However, where the numerical value expressed in SI Units is different from the value expressed in the units in current use results will, for some time, be reported both in SI and old units, eg, blood pressure: $100 \mathrm{mmHg}=13.3 \mathrm{kPa}$.

A list of references are given below for the aid of authors and readers and the March 1975 issue of $\mathcal{F M G}$ will carry a table of some relevant recommended SI Units.

\section{REFERENCES}

Baron, S. N. et al (1974). The use of SI units in reporting results obtained in hospital laboratories. Fournal of Clinical Pathology, 27, 590-597.

Baron, D. N. (1974). SI units. British Medical fournal, 4, 509-512.

The Symbols Committee of the Royal Society (1969). Symbols, Signs, and Abbreviations Recommended for British Scientific Publications. The Royal Society, London. (A new edition of this pamphlet is currently in preparation.) 